\title{
Comparison of Use of the Dalkon Shield in Dublin and Southampton
}

\author{
J. F. MILLER, R. SNOWDEN, J. T. LOUGHRAN, MAX ELSTEIN
}

British Medical fournal, 1975, 2, 599-601

\section{Summary}

The results of fitting Dalkon Shield I.U.D.s in Southampton and Dublin were compared. At 12 months the continuation rates were $77.4 \%$ and $93.4 \%$ respectively. There were also differences between the two cities in the major complication rates associated with the use of the device. At 12 months these rates for Southampton and Dublin were: pregnancy 5.6\% and $1.4 \%$, expulsion $4.0 \%$ and $0.9 \%$, and removal for pain and/or bleeding $12.1 \%$ and $3.0 \%$, respectively.

Possible reasons for the difference in performance may include the older average age of the users in Dublin, and the greater number and more varied experience of the medical staff responsible for fitting in Southampton. We recommend that population factors be taken into account when comparing data relating to fertility regulation.

\section{Introduction}

The increasing use of the intrauterine device (I.U.D.) as a

Faculty of Medicine, University of Southampton

J. F. MILLER, M.B., M.R.C.o.G., Lecturer in Human Reproduction and

MAX ELSTEIN, M.D., M.R.C.o.G., Senior Lecturer in Human Reproduction and Obstetrics

Family Planning Research Unit, University of Exeter

R. SNOWDEN, PH.D., D.S.A., Project Director

Family Planning Clinic, Dublin

J. T. LOUGHRAN, M.B., D.OBST.R.C.P.I., Chairman convenient and relatively effective method of contraception makes it increasingly important for the performance of different I.U.D.s to be known. Of even greater importance is to know whether the experience of one centre may be reliably used as a guide in the use of a particular I.U.D. in another centre. Reports on the use-effectiveness of the Dalkon. Shield ${ }^{1-4}$ have given pregnancy rates in the first year of use of between 1 and 5 per 100 users. In addition to factors associated with differences between the populations in these reports there are probablyother factors which may contribute to the differences in performance of this I.U.D. We have attempted to identify some of these factors.

\section{Method}

In Dublin, the Dalkon Shield was fitted within seven days of the beginning of a menstrual period in one of two clinics. Referrals were from general family planning sessions, general practitioners, specialists, and hospitals. All fittings were performed almost exclusively by two doctors.

In Southampton, fittings were undertaken in the Research Contraceptive Clinic by any one of a fairly large group of doctors, some of whom were family planning specialists, some trainee gynaecologists, and some trainee family planners. No specific time in the menstrual cycle was chosen for fitting so long as there was no indication that the patient had already conceived. Referral was from similar sources as in Dublin but in addition some patients were self-referred and some "problem" patients were accepted.

In both clinics the use of an adjunctive method, usually a spermicidal cream, was discussed with the patient with varying frequency. Follow-up in each clinic was of a similar pattern, the first follow-up visit being after six to eight weeks, and a follow-up check visit then being undertaken at six-monthly intervals. At each visit a standardized research form was completed and forwarded to the University of Exeter for statistical evaluation. Results were expressed using Tietze's life table approach. ${ }^{5}$ 


\section{Results}

Parity and Age.-Tables I and II show the age and parity of the women who accepted the Dalkon Shield in the two cities. A high proportion of the women in Southampton were of parities 1 and 2, the women in Dublin being generally of higher parity. The women in Dublin also tended to be older, only $49.5 \%$ being less than 30 compared with $67.5 \%$ in Southampton.

Event Rates.-The net cumulative event rates at $6,12,18$, and 24 ordinal months are shown in table III.

Events by Age and Parity.-The net cumulative event rates at six months are shown in table IV. Each acceptor is placed in one of four groups for age (under 30 and 30 and over) and parity (parity 1 or 2 and parity 3 or more).

Adjunctive Methods.-The proportion of women advised about an adjunctive method is shown in table V.

TABLE I-Age Distribution of Women at Fitting

\begin{tabular}{c|c|c}
\hline Age (Years) & Dublin & Southampton \\
\hline$<20$ & $0 \cdot 9 \%$ & $5 \cdot 1 \%$ \\
$20-24$ & $14.5 \% \%$ & $27.7 \%$ \\
$25-29$ & $34 \cdot 1 \%$ & $34.7 \%$ \\
$30-34$ & $29 \cdot 3 \%$ & $18.6 \%$ \\
$35-39$ & $15.4 \%$ & $9 \cdot 3 \%$ \\
$40-44$ & $5 \cdot 0 \%$ & $3.8 \%$ \\
$\geqslant 45$ & $0 \cdot 7 \%$ & $0.8 \%$ \\
\hline Total fittings & 2729 & 501 \\
\hline
\end{tabular}

TABLE II-Parity Distribution of Women at Fitting

\begin{tabular}{c|c|c}
\hline Parity & Dublin & Southampton \\
\hline 0 & $0 \cdot 1 \%$ & $4 \cdot 0 \%$ \\
$1-2$ & $26.9 \%$ & $60.5 \%$ \\
$3-4$ & $41.3 \%$ & $29.2 \%$ \\
$\geqslant 5$ & $31 \cdot 6 \%$ & $6 \cdot 3 \%$ \\
\hline Total fittings & 2729 & 501 \\
\hline
\end{tabular}

\section{Discussion}

The Dalkon Shield was related to higher event rates in Southampton than in Dublin (table III). The estimated continuation rate after one year was $77.4 \%$ in Southampton compared with $93.4 \%$ in Dublin. The major reasons for discontinuance in both centres were attributed to removal of the device because of pain and/or bleeding problems, expulsion, and unplanned pregnancy. The pattern was similar in both centres, with removals for bleeding and pain being about three times the expulsion rate at 12 months, but the incidence was different.

The pregnancy rate in Southampton was much higher than in Dublin, though the difference did not remain constant. Most pregnancies in Southampton occurred in the first few months after the device had been fitted. The pregnancy rate was five times as high after six months of use, falling to about three times as high at 18 and 24 months. The greater number of women in Dublin using an adjunctive method, especially in the early months, may have contributed to this changing difference (table V). A further factor that may help explain the difference in pregnancy rates is the difference in ages between the two groups (table I). Increasing age is associated with a lower pregnancy rate. ${ }^{6}$

TABLE v-Suggested Use of Adjunctive Methods

\begin{tabular}{|c|c|c|c|c|}
\hline & \multirow{2}{*}{$\begin{array}{l}\text { Pregnancy Rate at } \\
12 \text { Months per } 100 \\
\text { Users ( } \pm \text { S.E.) }\end{array}$} & \multicolumn{3}{|c|}{ Additional Method Advised? } \\
\hline & & Yes & No & Not Known \\
\hline $\begin{array}{l}\text { Dublin } \\
\text { Southampton }\end{array}$ & $\begin{array}{l}1 \cdot 4 \pm 0 \cdot 2 \\
6 \cdot 4 \pm 1 \cdot 2\end{array}$ & $\begin{array}{l}51.8 \% \\
16.9 \%\end{array}$ & $\begin{array}{l}35.9 \% \\
70 \cdot 0 \%\end{array}$ & $\begin{array}{l}12 \cdot 3 \% \\
13.1 \%\end{array}$ \\
\hline
\end{tabular}

The rate at which the Dalkon Shield was expelled from the uterus was much greater in Southampton but the pattern in the two centres was similar. Most expulsions occurred in the first three months after fitting, with few occurring after six months. The higher mean age of the Dublin users (table I) may partly account for this difference, as increasing age is associated with a lower expulsion rate (table IV). Increasing parity independent of age is not associated with an increasing expulsion rate despite the tendency for the cervix to be patulous. ${ }^{6}$ We suggest that a further reason for the higher expulsion rate in Southampton may be the greater number and more varied experience of medical staff responsible for fitting. Further evidence is needed, but with increasing numbers of doctors fitting I.U.D.s the performance of an I.U.D. in the community as a whole merits study.

The third major reason for discontinuing use of this I.U.D. was associated with complaints of pain and bleeding necessitating removal of the device. Removal in such cases is influenced by two factors, the attitude of the medical personnel fitting the device in relation to complaints of this nature and the motivation of the user. As with the other event rates the rate of removal

TABLE III-Net Cumulative Event Rates ( \pm S.E.) at Selected Ordinal Months of Use per 100 Users (Computed November 1974)

\begin{tabular}{|c|c|c|c|c|c|c|c|c|c|c|c|c|c|}
\hline \multirow{4}{*}{$\begin{array}{l}\text { Pregnancy } . . \\
\text { Expulsion ... } \\
\text { Removal: } \\
\text { Bleeding/pain } \\
\text { Other medical } \\
\text { Planning baby }\end{array}$} & & & \multirow{2}{*}{\multicolumn{3}{|c|}{ Ordinal months: }} & \multicolumn{4}{|c|}{ Dublin (2729 Fittings) } & \multicolumn{4}{|c|}{ Southampton (501 Fittings) } \\
\hline & & & & & & 6 & 12 & 18 & 24 & 6 & 12 & 18 & 24 \\
\hline & & & $\because$ & $\because$ & .. & $\begin{array}{l}0.8 \pm 0.2 \\
0.6 \pm 0.2\end{array}$ & $\begin{array}{l}1.4 \pm 0.2 \\
0.9 \pm 0.2\end{array}$ & $\begin{array}{l}2 \cdot 1 \pm 0.3 \\
0.9 \pm 0.2\end{array}$ & $\begin{array}{l}2.4 \pm 0.4 \\
0.9 \pm 0.2\end{array}$ & $\begin{array}{l}3.7 \pm 0.9 \\
3.5 \pm 0.8\end{array}$ & $\begin{array}{l}5 \cdot 6 \pm 1 \cdot 0 \\
4 \cdot 0 \pm 0.9\end{array}$ & $\begin{array}{l}5 \cdot 9 \pm 1 \cdot 1 \\
4 \cdot 0 \pm 0.9\end{array}$ & $\begin{array}{l}5 \cdot 9 \pm 1 \cdot 1 \\
4 \cdot 0 \pm 0.9\end{array}$ \\
\hline & $\begin{array}{l}\because \\
\because \\
\text { tion c } \\
\text { mainir } \\
\text { f obs }\end{array}$ & $\begin{array}{c}. . \\
\because \\
\text { ontinuing } \\
\text { ag } \\
\text { ervation }\end{array}$ & 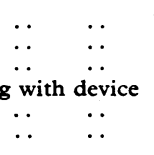 & $\begin{array}{l}\because \\
\because \\
\because \\
\because \\
\therefore\end{array}$ & $\begin{array}{l}. \\
\because \\
\because \\
\because\end{array}$ & $\begin{array}{l}1 \cdot 4 \pm 0 \cdot 2 \\
0.2 \pm 0.1 \\
0.3 \pm 0.1 \\
97.0 \\
2456 \\
15464\end{array}$ & $\begin{array}{c}3 \cdot 0 \pm 0 \cdot 4 \\
0 \cdot 4 \pm 0 \cdot 1 \\
1 \cdot 2 \pm 0 \cdot 2 \\
93 \cdot 4 \\
1688 \\
27477\end{array}$ & $\begin{array}{c}4 \cdot 9 \pm 0.5 \\
0 \cdot 6 \pm 0.2 \\
2 \cdot 7 \pm 0.4 \\
89 \cdot 3 \\
936 \\
34930\end{array}$ & $\begin{array}{c}7 \cdot 2 \pm 0 \cdot 6 \\
0.9 \pm 0 \cdot 2 \\
4 \cdot 2 \pm 0.5 \\
84.5 \\
345 \\
38430\end{array}$ & $\begin{array}{c}5 \cdot 3 \pm 1 \cdot 0 \\
0.8 \pm 0 \cdot 4 \\
0 \cdot 4 \pm 0 \cdot 3 \\
88 \cdot 3 \\
392 \\
2640\end{array}$ & $\begin{array}{c}12 \cdot 1 \pm 1 \cdot 5 \\
1 \cdot 3 \pm 0.5 \\
3 \cdot 6 \pm 0.8 \\
77 \cdot 4 \\
287 \\
4609\end{array}$ & $\begin{array}{c}14 \cdot 8 \pm 1 \cdot 7 \\
2 \cdot 2 \pm 0 \cdot 7 \\
5 \cdot 5 \pm 1 \cdot 1 \\
72 \cdot 6 \\
216 \\
6093\end{array}$ & $\begin{array}{c}17 \cdot 8 \pm 1 \cdot 9 \\
2 \cdot 8 \pm 0.8 \\
9.5 \pm 1 \cdot 4 \\
66.7 \\
144 \\
7163\end{array}$ \\
\hline
\end{tabular}

table IV-Net Cumulative Pregnancy, Expulsion, and Removal Rates ( \pm S.E.) According to Age and Parity per 100 Users at 6 Ordinal Months of Use

\begin{tabular}{|c|c|c|c|c|c|c|c|}
\hline & & \multicolumn{3}{|c|}{ Low Parity (1 or 2 ) } & \multicolumn{3}{|c|}{ High Parity ( 3 and Over) } \\
\hline & & Dublin & Southampton & U.K.* & Dublin & Southampton & U.K.* \\
\hline $\begin{array}{l}\text { Age under } 30 \text { years } \\
\text { Age } 30 \text { years and over }\end{array}$ & 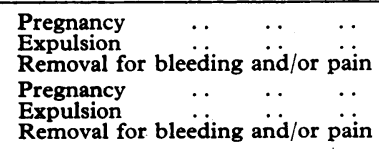 & $\begin{array}{c}0.2 \pm 0 \cdot 2 \\
0.2 \pm 0 \cdot 2 \\
1 \cdot 3 \pm 0.5 \\
0 \\
0 \\
1 \cdot 4 \pm 1 \cdot 0\end{array}$ & $\begin{array}{l}3 \cdot 2 \pm 1 \cdot 2 \\
4 \cdot 5 \pm 1 \cdot 4 \\
5 \cdot 0 \pm 1 \cdot 5 \\
2 \cdot 9 \pm 2 \cdot 0 \\
1 \cdot 5 \pm 1 \cdot 4 \\
4 \cdot 8 \pm 2 \cdot 6\end{array}$ & $\begin{array}{l}1 \cdot 6 \pm 0.4 \\
2 \cdot 3 \pm 0.4 \\
2 \cdot 1 \pm 0 \cdot 4 \\
1 \cdot 1 \pm 0.6 \\
1 \cdot 2 \pm 0.6 \\
2 \cdot 8 \pm 0.9\end{array}$ & $\begin{array}{l}1 \cdot 6 \pm 0.5 \\
0.9 \pm 0.4 \\
1.3 \pm 0.4 \\
0.8 \pm 0.3 \\
0.8 \pm 0.3 \\
1.5 \pm 0.4\end{array}$ & $\begin{array}{l}4 \cdot 0 \pm 2 \cdot 2 \\
2 \cdot 5 \pm 1 \cdot 8 \\
6 \cdot 3 \pm 2 \cdot 8 \\
5 \cdot 9 \pm 2 \cdot 5 \\
4 \cdot 4 \pm 2 \cdot 2 \\
3 \cdot 5 \pm 1 \cdot 9\end{array}$ & $\begin{array}{l}1.9 \pm 0.5 \\
1.2 \pm 0.4 \\
1.6 \pm 0.4 \\
1.6 \pm 0.4 \\
1.0 \pm 0.3 \\
1.8 \pm 0.4\end{array}$ \\
\hline
\end{tabular}

*Extrapolated from report No. 7 (Feb. 1974) of the Family Planning Research Unit, University of Exeter (Ref. ๑). 
because of pain and/or bleeding was considerably greater in Southampton than in Dublin. Interestingly, however, the incremental rate over consecutive three-month periods in each city was similar during the first year of use (Dublin $0.8 \%$, $0.6 \%, 0.7 \%$, and $0.9 \%$, and Southampton $2.7 \%, 2.6 \%, 3.8 \%$, and $3.0 \%$ respectively for each period). The rate of removal was not high during the first few months of use. The larger number of doctors in the Southampton clinic is bound to lead to a wider range of attitudes towards bleeding and pain, whereas the Dublin clinic arrangement leads to a more uniform approach.

There is another important difference between the two cities. Southampton has a liberal policy towards sterilization and termination of pregnancy for failed contraception which cannot be matched in Dublin. This gives an alternative outlet for the patient with I.U.D. complications, which tends to reduce motivation for a method such as the I.U.D. The lack of such alternatives in Dublin may force the I.U.D. user to tolerate discomfort at a level which would be unacceptable to the Southampton woman. The total family planning organization in terms of the range of alternatives in a given population must therefore be taken into consideration when examining any particular method of fertility regulation.

We acknowledge the help of the clinic staff in Southampton and Dublin and the data processing staff of the Family Planning Research Unit, University of Exeter, without whom this study would not have been possible.

\section{References}

1 Davis, H. J., American fournal of Obstetrics and Gynecology, 1970, 106, 455. 2 Davis, H. J., and Lesinski, J., Obstetrics and Gynaecology, 1970, 36, 350. Jones, R. W., Parker, A., and Elstein, M., British Medical fournal, 1973, 3, 143.

4 Snowden, R., and Williams, M., Contraception, 1973, 7, 91.

5 Tietze, C., Studies in Family Planning, 1967, 18, Suppl., p. 1.

Snowden, R., and Williams, M., Dalkon Shield Field Trial in United Kingdom, 2nd Report, Family Planning Research Unit, Report No. 7. University of Exeter, 1974.

\title{
Hospital Topics
}

\section{Screening for Hypothyroidism in Elderly Inpatients}

\author{
M. BAHEMUKA, H. M. HODKINSON
}

British Medical fournal, 1975, 2, 601-603

\begin{abstract}
Summary
Routine biochemical screening for hypothyroidism in 2000 geriatric inpatients proved valuable and practicable and yielded 46 cases $(2 \cdot 3 \%)$. A non-specific clinical picture was particularly common, with less than a third of the cases showing "typical" signs and symptoms. Psychiatric manifestations, especially depression, were important and frequent and responded well to thyroxine. There was a preponderance of female cases of hypothyroidism and a strong association with other autoimmune diseases, notably pernicious anaemia and rheumatoid arthritis.
\end{abstract}

\section{Introduction}

Hypothyroidism is common in old age. We started routine screening tests for thyroid dysfunction in all patients admitted to the geriatric department of Northwick Park Hospital in 1970. The early experience, based on 300 patients, suggested that the incidence of both hypothyroidism and hyperthyroidism was higher than had been previously reported, ${ }^{1}$ and we were thus encouraged to continue with screening.

When 2000 patients had been screened we re-examined our findings to see whether the earlier estimate of the incidence of hypothyroidism was reliable, but also to study the clinical picture of hypothyroidism in the elderly. We expected that this might be

\footnotetext{
Geriatric Department, Northwick Park Hospital, and Clinical Research Centre, Middlesex HA1 3 UJ

M. BAHEMUKA, M.B., M.R.C.P., Registrar (Present address: National Hospitals for Nervous Diseases, Maida Vale Hospital, London W.9) H. M. HODKINSON, B.M., F.R.C.P., Consultant
}

different from the textbook picture, which tends to be confirmed by series relying heavily on clinical diagnosis but might not be confirmed by the present series, in which identification was made on the basis of routine biochemical screening.

\section{Patients and Methods}

Generally in the department ${ }^{2}$ there is no waiting list, so that admissions include many cases of acute illness. Female admissions form $64 \%$ of the total, and the average age of the patients is 80 years, all being over 60. During the first 18 months the screening tests were the determination of protein-bound iodine (P.B.I.) by Auto Analyzer, and T-3-uptake by the Thyopac-3 test kit. Subsequently P.B.I. was replaced by T-4 estimation with the Thyopac-4 kit. In the interpretations we used a calculated free thyroxine index (F.T.I.), which is essential in view of the frequency of disturbance of thyroxine-binding proteins in these patients. ${ }^{3}$ Two or more separate abnormally low F.T.I.s were minimum requirements in all but the most clinically obvious cases, in which a single low value was accepted. Determination of thyroid-stimulating hormone ( $\mathrm{TSH}$ ) by a double antibody radioimmunoassay technique ${ }^{4}$ was used as a confirmatory test, while thyroid antibodies were sought in selected cases. Response to treatment also provided important confirmatory evidence.

The series represented about $95 \%$ of all patients admitted to the department, the remainder being largely accounted for by early deaths or patients who had been recently screened during a previous admission.

\section{Results}

Of the 2000 patients screened $46(2 \cdot 3 \%)$ were found to have undoubted hypothyroidism, this being a new diagnosis in 42 and representing relapse due to cessation or inadequacy of treatment in four. Where P.B.I. had been used the average F.T.I. was 1.85 compared with a normal range of $2 \cdot 8-7 \cdot 8,{ }^{3}$ and where $T-4$ had been used the average F.T.I. was 0.40 compared with a normal range of $0.55-1 \cdot 60$. None of the hypothyroid patients had had thyroid surgery or radioactive 